\title{
Current Situation and Countermeasures of Agricultural Information Construction in Jiamusi Area
}

\author{
Dongwei Shao*, Junfa Wang, Donghua Jiang, and Qisheng Liu \\ College of Mechanical Engineering, Jiamusi University, Jiamusi, \\ Heilongjiang Province, P.R. China 154007, \\ Tel.: 0454-6553306; Fax: 0454-8550757 \\ sdwshao@126.com
}

\begin{abstract}
Beginning with the current situation of agricultural information construction in Jiamusi area, the achievements obtained from agricultural information construction are clearly known by discussing current work conditions. On the basis of thorough investigation, the existing problems of agricultural information construction are found. The reasons of these problems are analyzed in detail, and then the general idea of agricultural information construction is laid out in this paper. At last, aiming at how to develop agricultural information construction, the feasible measures are proposed from the aspects of strengthening infrastructure construction, enhancing the quality of talent teams and integrating information resources.
\end{abstract}

Keywords: Jiamusi, agricultural information construction, current situation, countermeasures and suggestions.

\section{Introduction}

Agriculture is the foundation of the national economy, and agricultural information is an important aspect of the national information. However, China is still at the primary stage of socialism, and the degree of agricultural information is not very high, especially for the relatively backward region, Jiamusi. Significant development has been made in agriculture and the problem of food and clothing is basically solved after 30 years development of China's reform and opening up. However, to Jiamusi region, because of more agricultural population, relatively backward economic development level, geographical remoteness and larger proportion of agricultural production, the production concept of peasant is relatively backward; information exchange is poor; the quality of the farmers is generally low;agriculture production remains at the traditional stage and so on. To solve these problems, it is necessary to reform the traditional mode of agricultural development and to use agricultural information to promote agricultural modernization.

\footnotetext{
${ }^{*}$ Corresponding author.
} 


\section{The Main Problems of Agricultural Information and Running Status of Jiamusi Area}

\subsection{The Operational Status of Agricultural Information of Jiamusi Area}

Agricultural information construction in Jiamusi starts late, but in recent years some progress has been made in the construction of infrastructure, information services system and the areas of application of information technology under the guidance of the national and provincial ministries and commissions.

\subsubsection{Infrastructure Construction and Network Service Functions Have Been Increasingly Improved}

All the administrative villages of Jiamusi have telephones, the rate reaching $96 \%$, and the telephone network has reached 804 villages; the number of having phones is 136,806 . Currently more than 800 villages have realized broadband Internet access in the city; the rate of the villages having broadband network is more than $80 \%$.Towns and counties throughout the city are built in cable transmission networks, and cable networks have been built more than $3000 \mathrm{~km}$. Up to now, the total of radio and television agencies in the city is 70 ; the number of township and village having radio and television is the 70 and 948. Radio coverage of the city's population is 94.6 percent; the coverage of television population is 94.5 percent, and cable television subscribers reached $70 \%$, basically formating a CCTV, Heilongjiang TV programs as the main body, radio and television, wireless and wired, and FM, satellite and network, such as the combination of a variety of technical means, differently covered by TV networks and radio transmission coverage.

\subsubsection{The Channels of Information Dissemination Continue to Be Broaden}

Agricultural Information Service Station of the city opens the "Sanjiang Agriculture" web site. "Three-River Agriculture" plate is the Jiamusi city government Web site's main section. The plate has opened up superior crops and leading products, and farmers are guided by new products, new projects and the supply and demand of information, market price information to adjust the industrial structure, so as to sell grain; by taking full advantage of online information in agriculture, selecting information and opening up the page, column, feature, etc., releasing all the information to the grass roots and the majority of farmers through traditional media ( television, radio, newspapers, magazines, etc.).

\subsubsection{The Market of Information Showed a Prototype and Online Transactions Achieved Initial Success}

With the increasing agricultural restructuring, regional characteristics, industry characteristics, product characteristics are gradually emerging. Everywhere the Internet tools of the modern information transmission are in the full use, and agricultural production is actively done, in particular the work of characteristic online products, on-line market of agricultural products has been taking shape now, online sales become a larger scale. So far, the city's internet agricultural products have reached more than 300 , playing an active role in broadening the market of agricultural products and increasing the promotion of farmers. 


\subsection{The Main Problems of Agricultural Information of Jiamusi}

Jiamusi agricultural information construction is characterized by late start, but the pace of development is relatively fast. The problem is still very prominent, and the concrete embodiment is in the following areas.

\subsubsection{The Construction of Agricultural Information Is Understood Lackly}

From the investigation of the county and township government, the situation is prevailing, which is understanding not in place, not enough attention. The diversity of the information services systems is not recognized, forming one-sided understanding of the single information service system, not conducive to the effective transmission of information; the network functions generally stay in using networks to send and receive information, do not play the role of using network information to improve operating and developing markets; from the survey of the leading enterprises, because of the size of the business, product sales object, as well as the different qualities of business leaders, and its different understanding of the network. Some enterprises of large-scale and a large proportion exports in city outskirts attach great importance to the network; but other strong traditional concept enterprises of small scale and low overall quality, rarely keep in touch with domestic and international market, also its awareness of using the network is not strong, not paying enough attention. The role of agricultural associations and the rural economy organizations has not fully developed. From the investigation of farmers, a small number of farmers pay more attention to the construction of agricultural information, so they benefit a lot from the network in actual production. Most farmers are still not aware of the role of networks informatizing, needing to step up publicity.

\subsubsection{Agricultural Information Technology Infrastructure Is Relatively Backward}

Jiamusi region is a less developed region, with limited revenue, the state investing less, which leads to the fact that the construction of agricultural information of Jiamusi region is poured less and less. So now the lack of personnel training, hardware and software equipment changing and the follow-up input of technology up grades have a direct impact on the daily operation after the completion of the site, resulting in low levels of information technology work. At the same time, a comprehensive information database and system are not healthy enough, low information exchange and a low degree of resource sharing. Network market of agricultural products having realized online trading has not yet formed, and the development and application agricultural geographic information systems, satellite remote sensing information system are still at the infancy stage.

\subsubsection{Lack of Personnel in Agricultural Information}

The requirements of the quality of personnel on the construction of agricultural information and other information industry have obvious differences. The construction of agricultural information needs the "compound" talents who are skilled in agriculture using a variety of information tools, also understanding internet 
information technology. There are many agricultural experts among agricultural population of the county and township levels in our city, and there are some technicians understanding computer, but the "compound" talents who know computers and agriculture are not enough, which does not suit the development of agricultural information needs in the new period.

\section{The Countermeatures and Suggestions of Agricultural Information Construction in Jiamusi Area}

\subsection{Strengthen the Leadership and Advocacy Efforts of Agricultural Information Construction}

Information technology in rural areas is an inter-departmental, cross-sectional, regional and multi-technology integration of business systems engineering, related to all aspects. All levels of government must strengthen the unified leadership of the construction of agricultural information work, proceeding from actual conditions, and firmly establishing the concept of information, recognizing that information is the resources, that is, the idea of wealth. Government must attach great importance to establishing a strong leadership system, and strengthen the organization of agricultural information management.Set up a special organization to further raise awareness, clear responsibility to implement the task. All departments should coordinate with each other to form a work force, take effective measures to ensure that capital investment, technical guidance, supervision and management are "three in place".

\subsection{Establish the Construction of System Including Government, Science and Education Units, Associations, Enterprises (Information Enterprises, Agriculture-Related Enterprises) and Individuals, Households}

Counties (cities) and districts of the city unify development and management of the rural information resources system, unify the training and management of agricultural information in accordance with the development of information construction in rural areas and rural implementation of integrated information service system in the overall program requirements and plans from actual situation to solve the organizational issues, personnel issues and financial implications of the agricultural information questions. Enhance the development and utilization of agricultural information resources and accelerate the pace of construction of agricultural information and close around the optimization of agricultural structure, improving the rural ecological environment, the dissemination of agricultural science and technology knowledge, the publishment of information about agricultural products and the increase of agricultural income of the farmers, paying close attention to implementation, and paying close attention to efforts. At the same time, we should also make full use of news media, such as radio, television, publicity boards, network and so on, to promote important role on the construction of agricultural information further and extensivly in agricultural growth, farmers' income, and further promote the popularization of 
information technology knowledge, continuously improve their understanding of information technology so that farmers benefit from them, happy to accept. The role of the media should be fully played; the extent of participation of the farmers' agricultural information should be improved, carry out a variety of publicity and education, accelerate the popularization of information knowledge. At the initial stage of information of the rural areas, government departments should actively guide, increase investment, establish a diversified investment and financing mechanism, improve management supporting system of the construction of agricultural information, assume the main role of agricultural information, promote the building of agricultural information, and improve the face of relatively backward of the rural areas, create the conditions for farmers to abandon the old production modes, to accept new concepts, to find new ideas.

\section{The General Idea of Scientific Planning on the Construction of Agricultural Information Work in Jiamusi}

In the next few years, agricultural information construction in Jiamusi region must take accomplishment of the agricultural modernization as the goal, take the market as the guidance, take science and technology as support, take the revitalization of northeast old industrial base as an opportunity, stand on a high degree of development of the future agricultural globalization, knowledge and commercialization, further establish and improve the agricultural information network system, strengthen the information services function, fully provide the trend of agricultural products and markets, rural economic information and technical information on agricultural production; strengthen the agricultural database building, information analysis and forecast release; take Jiamusi city as the core, take Huanan City and Fujin County as the wings, make full use of advantages of modern agricultural demonstration base construction on Jiansanjiang and Hongxinglong farms Authority, guided by the principle of the "one plan, the implementation step by step, constructs while uses, and high-performance running ", strive for a high planning starting point, novel methods, and bright features, and drive the development of agricultural information work around the cities and counties. At the same time, agricultural information construction in Jiamusi region must be guided by the principle " in the light of local conditions and classified instruction", further establish and improve the agricultural information system, get a current foothold, focus on long-term benefits, and achieve a modest investment, convenient operation, prompt and effective goal. In the network construction, the professional production base, agricultural products market, leading enterprises, the certain scale cooperative economy organization, the farmer managers and the agricultural wealthy and powerful family networking work should be together integrated to the plan as key. In the resources construction, various aspects strength should be conformed, and the city county agriculture information resource unit exploitation pattern should be established, and the information resource on-line exchange, on-line issue and on-line propaganda should be overall considered. In the 
information issue, the concrete time, the way and the content should be thoroughly considered and arranged, and thus the whole city agriculture information network's integrated function will be truly displayed.

\section{Acknowledgements}

The first author is grateful to the Jiamusi University for providing her with pursuing a Master's degree at the Jiamusi University. 